\title{
Erratum to: Modeling stimulus variation in three common implicit attitude tasks
}

Katie Wolsiefer $^{1} \cdot$ Jacob Westfall ${ }^{2} \cdot$ Charles M. Judd $^{1}$

Published online: 13 April 2017

(C) Psychonomic Society, Inc. 2017

Erratum to: Behav Res

DOI 10.3758/s13428-016-0779-0

The R code for the IAT model in the Appendix should be:

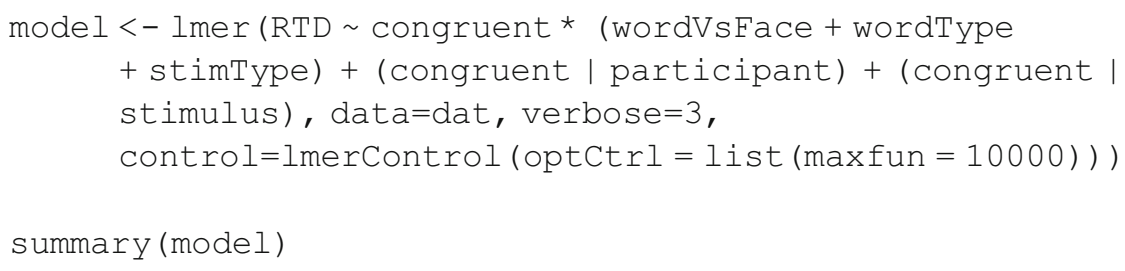

This code is given correctly in the online/HTML version of the article, but not in the PDF version.

The online version of the original article can be found at http://dx.doi.org/ 10.3758/s13428-016-0779-0

Katie Wolsiefer

katherine.wolsiefer@colorado.edu

1 University of Colorado, Boulder, CO, USA

2 University of Texas, Austin, TX, USA 